In: Strategic Engineering for Cloud Computing and Big Data Analytics.

Hosseinian-Far A, Ramachandran M, Sarwar D (eds.),

Springer International Publishing, pp. 3-27 ISBN:978-3-319-52490-0

\title{
Mathematical and Computational Modelling Frameworks for Integrated Sustainability Assessment (ISA)
}

\author{
Maryam Farsi, Amin Hosseinian-Far, Alireza Daneshkhah and Tabassom Sedighi
}

\begin{abstract}
Sustaining and optimising complex systems are often challenging problems as such systems contain numerous variables that are interacting with each other in a nonlinear manner. Application of integrated sustainability principles in a complex system (e.g. the Earth's global climate, social organisations, Boeing's supply chain, automotive products and plants' operations, etc.) is also a challenging process. This is due to the interactions between numerous parameters such as economic, ecological, technological, environmental and social factors being required for the life assessment of such a system. Functionality and flexibility assessment of a complex system is a major factor for anticipating the systems' responses to changes and interruptions. This study outlines generic mathematical and computational approaches to solving the nonlinear dynamical behaviour of complex systems. The goal is to explain the modelling and simulation of system's responses experiencing interaction change or interruption (i.e. interactive disruption). Having this knowledge will allow the optimisation of systems' efficiency and would ultimately reduce the system's total costs. Although, many research works have studied integrated sustainability behaviour of complex systems, this study presents a generic mathematical and computational framework to explain the behaviour of the system
\end{abstract}

Maryam Farsi

Operations Excellence Institute, School of Aerospace, Transport and Manufacturing, Cranfield University, Cranfield, MK43 0AL, UK, e-mail:maryam.farsiecranfield.ac.uk

Amin Hosseinian-Far

School of Computing, Creative Technologies \& Engineering, Leeds Beckett University, Leeds, LS6 3QR, UK, e-mail:A.Hosseinian-Far@leedsbeckett.ac.uk

Alireza Daneshkhah

The Warwick Centre for Predictive Modelling, School of Engineering, The University of Warwick, Coventry, CV4 7AL, UK, e-mail: A.Daneshkhah@warwick.ac.uk

Tabassom Sedighi

Energy Environment Food Complexity Evaluation Complex Systems Research Centre, Cranfield School of Management, Cranfield University, MK43 0AL, UK, e-mail: t.sedighi@ cranfield.ac.uk 
following interactive changes and interruptions. Moreover, a dynamic adaptive response of the global system over time should be taken into account. This dynamic behaviour can capture the interactive behaviour of components and sub-systems within a complex global system. Such assessment would benefit many systems including information systems. Due to emergence and expansion of big data analytics and cloud computing systems, such lifecycle assessments can be considered as a strategic planning framework before implementation of such information systems.

\section{Introduction}

Sustainability can be defined as sustaining, preserving and enhancing some valuable or valued condition(s) over time in a dynamic system (Brinsmead, 2005). The sustainability science studies the complex relationship between nature and society in a global environment so-called global system. This complex interaction can occur between a broad range of sub-systems such as economic, ecological, technological, environmental and social notations (Fiksel, 2003; Hosseinian-Far, Pimenidis, Jahankhani, \& Wijeyesekera, 2010). In the context of information systems, sustainability assessment is usually focused on the economy domain (Hosseinian-Far \& Chang, 2015a). For instance, the interplay between human activities in a society and economy affects economic growth or decay, the standard of living, poverty and etc. Moreover, the interaction between human behaviour and ecological systems tends to focus on global warming, energy security, natural resources and biodiversity losses and etc. Finally, the interplay between humankind's actions, knowledge and activities and technological environment improve or regress technology, increase or decrease safety and has effects on the healthiness of people's daily lives. Meanwhile, Integrated Sustainability Assessment (ISA) applies sustainable principles to provide and support policies and regulations and incorporate decision making in a global system across its lifecycle. Therefore, ISA can be a solution-oriented discipline to evaluate the behaviour of a complex global system. The complete discipline integrates a broad range of knowledge and methodologies towards defining solutions. In this context, the development of a robust and integrated framework for sustainability assessment is of paramount importance.

Understanding the sustainability concept is clearly the basis for sustainability assessment. Sustainability or Sustainable development was first described by the Brundtland's report titled 'Our Common Future' published by the World Commission on Environment and Development. The paper argued that sustainable development means "development that fulfils the needs of the present without compromising the ability of future generations to meet their own needs. This contains two key concepts. (i) The concept of 'needs' in particular the necessary requirements of the world's poor, to which overriding priority should be given, and (ii) the idea of limitations imposed by the state of technology and social organisation on the environment's ability to meet present and future need" (Brundtland, 1987). This argument tailed by several debates and discussions on how sustainability should be defined, 
interpreted and assessed (Pezzey, 1989). Sustainability assessment can be described as a process to identify and evaluate the effects of possible initiatives on sustainability. The initiative can be a proposed or an existing policy, plan, programme, project, piece of legislation, or a current practice or activity (Pope, Annandale, \& MorrisonSaunders 2004). Developing transformative lifecycle and system-oriented tools and methodologies both at national and international levels have been studied since late 80 's and earlier 90's. Multiple factors and indicators can reflect the complexity of a global system's behaviour. This motivated efforts to combine indicators into integrated, quantitative measures of sustainability called Integrated Sustainability Assessment (ISA) (Lal, Ghuman, \& Shearer. 1990).

In (1992), Altieri investigated the critical issues which had an effect on productive and sustainable agriculture in Latin America using integrated pest management programs as case studies. He discussed that the attainment of such agriculture is dependent on new technological innovations, policy changes, and more socioequitable economic schemes (Altieri, 1992). Furthermore, in (Elkington, 1994) the concept of Triple Bottom Line (TBL) has been added to the accounting perception by John Elkington (Elkington, 1994). The TBL framework considers the interaction between three parts: social, environmental (or ecological) and economic in one global business system as illustrated in Figure 1 Moreover, TBL introduced

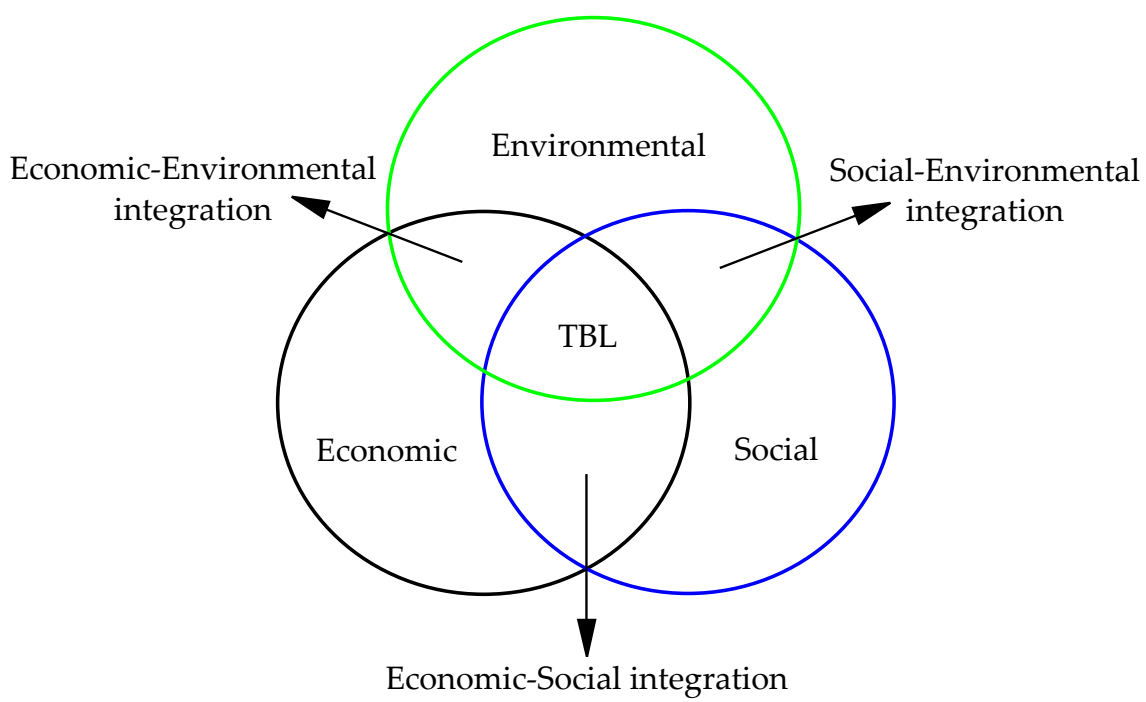

Fig. 1 The three pillars of sustainability or the three P's: People, Planet and Profit; TBL is an integrated interaction between the environmental, economic and social dimension of global sustainability.

three dimensions commonly called the three P's: People, Planet, and Profit into the sustainability concept (Elkington, 2004). This new impression became a favourite subject in sustainability which requires consideration of economic, social and natu- 
ral environmental parameters to characterise the valued conditions in sustainability (Hosseinian-Far \& Jahankhani 2015b). Smith and McDonald (1997) presented that agricultural sustainability assessment encompasses biophysical, economic and social factors. Therefore, they considered more parameters to assess the agricultural sustainability using multiple qualitative and quantitative indicators (Smith \& McDonald, 1997). In the late 90 's and early $20^{\text {th }}$-century sustainability assessment has been developed by including the integrated sustainability science theory. In 1996, Rotmans and Asselt described integrated assessment as "integrated insights to decision makers" (Rotmans \& Asselt, 1996). In this context, integration definition considers the combination of different parameters, functions, policies and regulations into a whole global system in an appropriate way that achieves a particular goal and purpose within the system. Integrated Sustainability Assessment (ISA) necessitates the following characteristics: (i) It should be conducted with explicit awareness of the global system; (ii) It should be directed by comprehensive aims, policies and regulations preferably explicitly articulated though initially less specifically; (iii) It usually requires stakeholder's involvement due to the significant influence of the policies and outcomes evaluation criteria on the direction of an integrated sustainability assessment; (iv) Sustainability assessment criteria are dynamic, time dependant and will change over time; (v) Integration is expensive since it necessitates a significant amount of time and different resources (Brinsmead, 2005).

As mentioned earlier, assessment of integrated sustainability is a complex process due to the diversity of variables, parameters, formulations, policies and regulations in a global system. Sustainability assessment provides information for decision-makers to decide what action they should take or what policy they should apply within the system to make society more sustainable. The integrated assessment arises from Environmental Impact Assessment (EIA) and Strategic Environmental Assessment (SEA). However, SEA has been divided into economic and social approaches as well as the environmental aspect, which still reflects the Triple Bottom Line (TBL) approach to sustainability (Hacking \& Guthrie, 2008). The overal aim of sustainability assessment is mainly to minimise unsustainability with respect to TBL objectives (Pope et al. 2004, Bertrand et al., 2008). Moreover, sustainability assessment can be conducted to evaluate a policy implementation into a system to inform, advise and update a management practice within the system. This study focusses on both mathematical and computational integrative methods within sustainability assessment. This multi-functionality and multiplicity of sustainability assessment terminologies and methodologies can be confusing. Therefore, this research study proposes a generic framework for the corresponding strengths of numerous approaches and methods which can be used by industrial ecologists and engineers and ecological and biophysical economists. This generic framework can also be used as starting point for many computer scientists and relevant industries for lifecycle assessments and applications of computing emerging technologies and systems such as big data analytics, systems set up, around cloud services and Internet of Things (IoT). 


\section{Integrated Sustainability Assessment (ISA)}

This section discusses the triple pillars of sustainable development integration and describes the existing mathematical and computational methods concerning development of an integrated decision support system for sustainability assessment. In this context, the system is considered as a complex global system. As mentioned earlier, in a sustainable global system, the three pillars of sustainable development are Environmental, Economic (i.e. prosperity or profitability aspects) and Social. Initially, the characteristics and features of complexity in a system have been discussed by reviewing standard measures of complexity from relevant scientific literature. Then, in order to bring mathematical and computational flexibility and rigour to the issue, different statistical complexity measurements, and computational modelling features have been discussed.

A complex system is a system with numerous interdependencies in its structure. Such systems are sensitive to any small perturbations which may affect the initial conditions. In a complex system, the interactions between the independences and components are numerous. Therefore, the responses of the system to these perturbations and changes are not unique. Such behaviour is complex since the system can take multiple pathways to evolve. Moreover, the growth and development of a complex system may vary over time, and therefore this categorises such a system as a dynamic one. In this paper, the notion of complex dynamical system is denoted to a global system. A global system can be described as a System of Systems (SoS) which is composed of several sub-systems (Hosseinian-Far \& Chang, 2015a). Analytically, the behaviour of such a complex dynamical system can be derived by employing differential equations or difference equations (Todorov \& Marinova. 2011). The key features and properties that can be associated with a global system are nonlinearity, feedback, spontaneous order, robustness and lack of central control, hierarchical organisation, numerosity and emergence, (Ladyman, Lambert, \& Wiesner, 2013).

Although, nonlinearity is one of the features of a complex system, the behaviour of such system can also be linear where the corresponding parameters and objectives can be written as a linear sum of independent components. Meanwhile, linear studies can be used to understand the qualitative behaviour of general dynamical systems (Hosseinian-Far, Pimenidis, Jahankhani, \& Wijeyesekera, 2011). Analytically, this can be achieved by calculating the equilibrium points of the system and approximating it as a linear trend around each such point. Nonlinearity is often considered to be a vital characteristic of a complex system. The nonlinear system is a system that does not satisfy the superposition principle. The nonlinear behaviour of a global system becomes more complex regarding the diversity and variety of subsystems' properties, conditions, and boundaries other than sub-systems variations. For instance, the complexity of living organism as a global system with numerous properties of being alive or dead other than a variety of its sub-systems and components (e.g. Human organisms composed of trillions of cells which are clustered into particular tissues and organs). Mathematically, for such global systems, typically, 
it is required to generate nonlinear differential equations to explain their dynamic behaviour.

Feedback is an important feature of a global system since the interaction between sub-systems are dynamic and are changing over time. Therefore, the behaviour of a nonlinear dynamic system extensively depends on the accuracy of the relations and interactions between its components. One of the typical examples of such systems in this context is the behaviour of a colony of ants that interact with each other. The quantitative approach to model such a complex behaviour can be defined by a nonlinear first-order differential equation, so-called System Dynamics (SD) which will be discussed later in this chapter. Since a complex dynamical system can be composed of a large number of elements, identifying the order of interaction between these elements are difficult and not clear. The spontaneous behaviour of orders is one of the most perplexing problems to define the behaviour of the complex systems on the feedback and information processes within the system over time. Moreover, the orders in a complex system can be robust in the system due to the scattered origin. Despite the sensitivity of a global system to any perturbation, orders are stable under such conditions. For example, consider a group of flying birds as a global system; they stay together, and the order of the pathways they take do not change, despite for instance any internal disruption such as the individual motion of the members or external disruption caused by the wind. Mathematically, robustness can be formulated in a computational language as the capability of a complex system to correct errors in its structure (Shannon, 2001).

As mentioned earlier, a global complex dynamical system is composed of components and elements so-called sub-systems. Such structures can resemble the structure of a hierarchical organisation. Subsequently, numerosity is an inherent property of a complex structure referring to the numerous number of sub-systems and parts in one global system. In a complex system, there may be different levels of organisations with individual properties and features. Emergence can arise from a robust order due to the complex interaction between these organisations and sub-systems within the global system. In system theory, emergence process between sub-systems is fundamental of integrative levels and complex systems (Simon, 1991).

Hitherto, different characteristics and properties of a global system have been explained briefly. Consequently, integrated assessment contributed to the sustainability science through developing a framework for different analytical and computational methodologies considering uncertainties, lifecycle thinking, policies, plans, and regularities. In the following section, a different aspect of Integrated Sustainability Assessment (ISA) with regards to TBL is discussed, followed by introducing the related methodologies, models, tools, and indicators. Moreover, ISA can be developed to define and evaluate the relationships between environmental, economic and social dimensions intended for optimising the interactive outcomes considering the TBL boundaries and constraints. 


\subsection{Environmental Sustainability Assessment}

The environmental aspect of sustainability assessment is mainly viewed as ecological sustainability. The fundamental principles of environmental sustainability assessments focus on reducing the constructional embodied energy and $\mathrm{CO}_{2}$ emissions; reducing the lifecycle of atmospheric emissions (i.e. $\mathrm{CO}_{2}, \mathrm{NO}_{x}, \mathrm{SO}_{x}, \mathrm{CH}_{4}$, $\mathrm{N}_{2} \mathrm{O}$ and etc.) and the waterborne emissions (i.e. COD, BOD, Total P, Total $\mathrm{N}$ and etc.) and limiting the requirement for water, fossil resources and natural gas (Silalertruksa \& Gheewala, 2009). Environmental sustainability assessments can provide indicators and indices as qualitative measurements to represent the environmental development in a defined system (Hosseinian-Far et al., 2010). Indicators should be simple and transparent, measurable and quantifiable, sensitive to change and interruptions and time-dependent (Ness, Urbel-Piirsalu, Anderberg, \& Olsson, 2007). In particular, there are a number of environmental assessments developed by the Office for National Statistics (ONS). The UK's Office for National Statistics (ONS) is one of the largest independent national statistical institutes. One of the main tasks of ONS is to collect, develop and publish official statistics related to environment, economy, population, and society at national, regional and local levels (Office for National Statistics, 2013). According to the ONS, the headline 'environmental assessments' considers greenhouse gas emissions, natural resource use, wildlife: bird population indices and Water use. Moreover, the corresponding supplementary measures are as follows: UK CO2 emissions by sector, energy consumed in the UK from renewable sources, housing energy efficiency, waste, land use \& development, origins of food consumed in the UK, river water quality, fish stocks, status of species \& habitats and UK biodiversity impacts overseas (Office for National Statistics, 2013).

The main and fundamental benchmark for evaluating the impact of environmental dimension on sustainability can be done by assessing the environmental performance of a global system using Environmental Life- Cycle Assessment (LCA). However, this assessment is not sufficient to understand the dynamic and interactive behaviour of environmental and ecological impacts. LCA is a simplified quantitative approach based on the traditional linear behaviour of complex systems. Despite the LCA's limitations and challenges in obtaining qualitative data, LCA can be still considered as the most comprehensive approach for environmental impact assessment (Heijungs, Huppes, \& Guinée, 2010). The International Standards Organisation (ISO) is the institution that is responsible for establishing principles and guidelines for life-cycle assessment (Tibor \& Feldman, 1996) called ISO 14040:2006- Principles and Framework (ISO 14040:2006, 2006) and ISO 14044:2006-Requirements and Guidelines (ISO 14044:2006, 2006) for LCA. According to the ISO standards, life-cycle assessment falls into two distinct classes based on its origin as Economic Input-Output based LCA (EIO) and Ecologically based LCA (Eco-LCA). Moreover, the corresponding LCA terms and expressions are defined as follows:

- Life-cycle: "consecutive and interlinked stages of a product system, from raw material acquisition or generation of natural resources to final disposal". 
- Life-cycle assessment (LCA): "compilation and evaluation of the inputs, outputs and the potential environmental impacts of a product system throughout its lifecycle".

- Life-cycle inventory analysis (LCI): "the assessment involving the compilation and quantification of inputs and outputs for a product throughout its lifecycle".

- Life-cycle impact assessment (LCIA): "the assessment aimed at understanding and evaluating the magnitude and significance of the potential environmental impacts of a product system throughout the lifecycle of the product".

Therefore, the life-cycle assessment is carried out in four distinct phases as illustrated in Figure 2 These four phases are (i) Goal and scope definition, (ii) the Life-

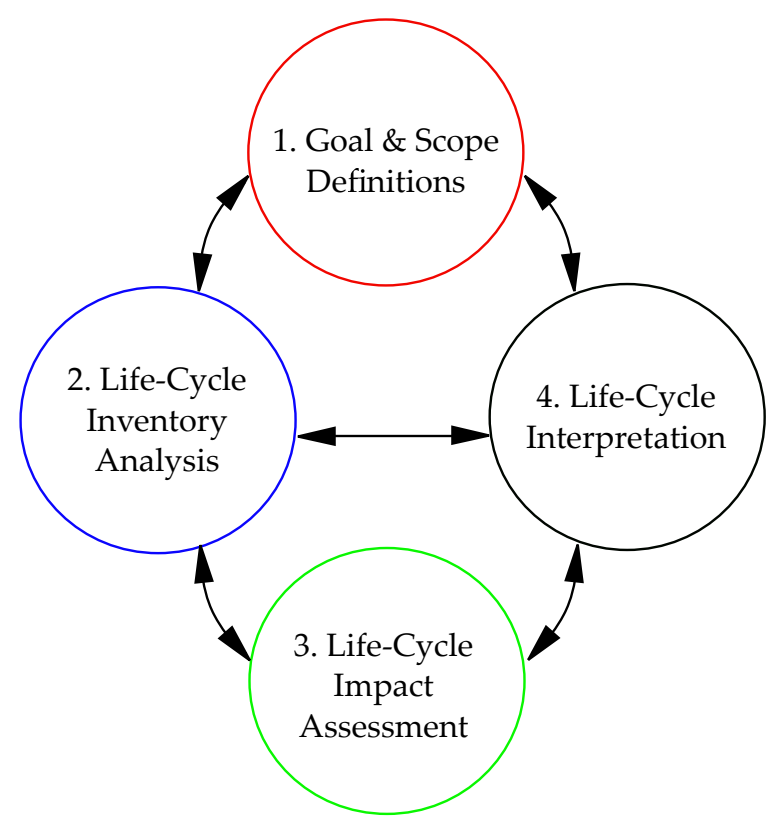

Fig. 2 Life-Cycle Assessment phases.

Cycle Inventory Analysis (LCI), (iii) the Life-Cycle Impact Assessment (LCIA) and (iv) the Life-Cycle Interpretation phase. Goal and scope phase focuses on identifying the aim of the LCA study and the corresponding objectives and applications with regards to the system boundaries, assumptions and constraints. Afterwards, in the inventory analysis phase, the essential data are collected to fulfil the objectives of the LCA study. The data collection can be achieved by inventorying the input and output data from the studied system. Subsequently, the results from inventory analysis are transformed into the corresponding environmental impacts such as utilisation of natural resources, human health and safety and etc. in the impact assessment phase. The final phase of the LCA study is lifecycle interpretation. In this phase, the results of the inventory and impact assessments are evaluated in order to provide infor- 
mation for decision makers which will ultimately help to develop essential policies and recommendations based on the goal and scope definition in the studied system. Recently, ISO published a general guideline on the implementation of ISO 14004 (2016) which applies to any organisation with respect to their environmental principles, products and delivered services.

Considering different lifecycle assessment approaches; Economic Input-Output Life-Cycle Assessment (EIO-LCA) method evaluates the required raw materials and energy resources, estimates the environmental emissions, and assesses the economic activities in a system. EIO-LCA is one of the LCA techniques for lifecycle assessment study which is helpful for evaluating environmental impacts of a product or a process over its lifecycle. This method has been invented and developed by Wassily Leontief in (1970). Economic Input-Output (EIO) theory introduces a mathematical modelling approach to systems lifecycle assessment and therefore can be beneficial to industry. It can be used for evaluating the financial transactions based on inputs and outputs within the sector. EIO model can be formulated as a matrix $X_{i j}$ which represents the financial transaction between sectors $i$ and $j$ in a particular year. Therefore, by using this method, the necessity of the input for an internal transaction in a sector can be indicated as (i.e.: $X_{i j} \neq 0$ where $i=j$ ). Moreover, the direct, indirect and total effects of alterations to the economy can be identified using linear algebra techniques (Leontief, 1970).

Consider matrix $A_{i j}$ as the normalized output amounts for sector $j$, so that $A_{i j}=$ $X_{i j} / x_{j}$. In addition, consider a vector of final demand, $y_{i}$, for the output from sector $i$. Therefore, the total output from sector $i, x_{i}$ can be calculated as the summation of the output from sector $j$ as a consumer and the total transaction between other sectors $X_{i j}$, thus:

$$
\begin{aligned}
x_{i} & =y_{i}+\sum_{j} X_{i j} \\
& =y_{i}+\sum_{j} A_{i j} x_{j},
\end{aligned}
$$

the vector notation of the Equation 1 is thus:

$$
x=y+A x \quad \Rightarrow \quad x=(I-A)^{-1} y .
$$

Material Flow Analysis (MFA) is an analytical method for quantifying stocks and flows of materials and entities within a system. MFA is capable of tracking the entities (e.g.: materials, productions and etc.) and evaluating their utilisation in a system. Combining traditional economic input-output modelling approach with material flow analysis creates a mixed-unit input-output analysis technique to track and evaluate the economic transactions under changes in productions (Hawkins, Hendrickson, Higgins, Matthews, \& Suh, 2007). The other method to estimate the direct and indirect resource requirements of a system is the well-known Physical and Monetary Input-Output (PMIO) method which evaluates all the physical flows associated with the system economy (Weisz \& Duchin, 2006). 
In addition to the methodologies and techniques discussed, in order to assess the economic aspect of the lifecycle, the Ecologically based Life-Cycle Assessment (Eco-LCA) method evaluates the role of ecosystem services in life-cycle assessment. Eco-LCA classifies resources into the following categories: (i) Renewable versus non-renewable, (ii) biotic versus abiotic, (iii) materials versus energy, or (iv) regarding their originating ecosphere (lithosphere, biosphere, hydrosphere, atmosphere, and other services). Eco-LCA is a physically based approach to assess the flows and interactions between considered resources in a system. For instance, Material Flow Analysis (MFA), Substance Flow Analysis (SFA) and Energy Flow Analysis (EFA) are some physical flow based assessments for Eco-LCA of a system. Material flow analysis focuses on biophysical aspects of human activity with a view to reducing environmental related losses. Substance flow analysis is an analytical method to quantify flows of certain chemical elements in an eco-system. However, energy flow analysis focuses on the flow of all types of energy such as exergy and emergy-based on the first law of thermodynamics.

\subsection{Economic Sustainability Assessment}

The second dimension of sustainability assessment is Economic Sustainability Assessment (ESA) which is focused on estimation of prosperity and profitability of a global system over its lifecycle (Halog \& Manik, 2011). ESA can be generated to estimate the required economic growth, necessary for maintaining the sustainability of a system. In particular, the economic dimension of sustainable development in the UK can be measured by the following benchmarks: economic prosperity, long-term unemployment, poverty and knowledge, and skills measure. Moreover, the supplementary measures are as follows: population demographics, debt, pension provision, physical infrastructure, research and development and environmental goods \& services sector (Office for National Statistics, 2013). One example of the economic indicators for monitoring economic prosperity is called Gross Domestic Product (GDP), which represents the scale of economic activities within the country. This indicator is developed by the UK Office of National Statistics (ONC). Similarly, Domestic Material Consumption (DMC) is an important indicator to measure resource productivity in the context of Europe 2020 strategy (European Union, 2014). DMC indicator relates to the gross domestic products which are developed by Statistical Office of the European Communities (Eurostat). Eurostat is the statistical office of the European Union and is responsible for providing statistics, accounts, and indicators supporting the development, implementation and monitoring of the EUs environmental policies, strategies and initiatives (Statistical Office of the European Communities., 1982). Moreover, Net National Product (NNP) is another economic indicator which represents the monetary value of finished goods and services. NNP can be calculated as the value of GDP minus depreciation. In accountancy, depreciation refers to the amount of GDP required to purchase new goods to maintain existing. GDP and NNP are the two most frequently used benchmarks by decision 
makers, are defined to measure and assess the overall human welfare (Ness et al., 2007).

Life-Cycle Cost Analysis (LCCA) is the most powerful benchmark for evaluating the economic impact of sustainability. LCCA is applied to evaluate the economic performance of a system over its entire life. The cost assessment considers the total cost including the initial cost, operating and service cost, maintenance cost and etc. Therefore, identifying activities and subsequently, the associated costs is the initial requirement for conducting the lifecycle assessment study. Although, the Environmental Life-Cycle Assessment (ELCA) methodologies where the focus was on the material, energy and resources flow, within the Life-Cycle Cost Assessment (LCCA) money flows would be the main focus. Furthermore, the Full Cost Environmental Accounting (FCEA) is another lifecycle costing analysis method. Both LCCA and FCEA approaches assess the environmental cost, and therefore they are appropriate methods for evaluating the economic impacts of sustainability. Within the context of information systems, this pillar of sustainability is the major context where sustainability and resilience of the system are assessed. Hosseinian-Far and Chang outlined the metrics required for assessing the sustainability of selected information systems. It is also argued that such economic sustainability assessment of information systems and the use of metrics is context dependent (Hosseinian-Far \& Chang, 2015a).

\subsection{Social Sustainability Assessment}

The third pillar of sustainability assessment is referred to as Social Sustainability Assessment (SSA). This assessment provides measures and subsequently guidelines required for identifying social impacts on sustainability assessment in a global system. In this context, a global system is composed of numerous entities. These entities can be organisations, individuals, shareholders, stakeholders, and etc. In such a system these entities have an obligation to provide services and actions for the benefit of society as a global system. This responsibility is called Social Responsibility (SR). In another word, SR is a duty every entity has to perform so as to maintain a balance between the economic and the ecosystems (Benoît et al. 2010a). According to the UK Office for National Statistics (ONS), the following measures are the social benchmarks of sustainable developments: healthy life expectancy, social capital, and social mobility in adulthood and housing provision. Furthermore, supplementary social indicators are as follows: avoidable mortality, obesity, lifestyles, infant health, air quality, noise and fuel poverty.

Social Life-Cycle Assessment (SLCA) is the third dimension of life-cycle sustainability assessment which assesses the social and sociological impact of an organisation, individuals, and products along the lifecycle (Finkbeiner, Schau, Lehmann, \& Traverso, 2010). In addition, the Millennium Ecosystem Assessment (MEA) estimates the impact of ecosystem changes on human well-being by considering health and security, social relations, freedom and etc. (Benoît et al., 2010a). These social 
aspects are gathered and developed by the Sustainable Consumption and Production (SCP) in order to generate and implement the corresponding policies and actions for public and private decision makers. However, identifying and evaluating social aspects are challenging since some of the social performance data are not easily quantifiable (Schaltegger, Bennett, \& Burritt, 2006). These aspects can be categorised as human rights, working condition, health and safety, cultural heritage, education, and etc. (Benoît \& Vickery-Niederman, 2010).

Regarding the society impacts on sustainability assessment, the Joint United Nations Environment Programme (UNEP) and the Society of Environmental Toxicology and Chemistry (SETAC) develop knowledge and provide support in order to put lifecycle thinking into effective practices. This international lifecycle partnership is known as the Life-Cycle Initiative (LCI), established in 2002 (Jolliet et al., 2003). SETAC is a worldwide and not for profit professional society that its main task is to suppport the development of principles and practices for support, improvement, and management of sustainable environmental quality and ecosystem integrity (SETAC 2016). Whereas, the UNEP as the leader of global environmental authority develops and implements the environmental dimension of sustainable development within the United Nations (UN) system and intends to support the global environment (Finkbeiner et al., 2010; Benoît \& Vickery-Niederman, 2010).

Social assessment techniques and methodologies focus on improvement of social conditions since the main goal in SLCA is enhancing human well-being (Benoit et al. 2013). Human well-being can be evaluated through many indicators and terms. The most common ones are human development, standard of living and quality of life. For instance, Human Development Index (HDI) is an integrated indicator composed of life expectancy, education and income used by the United Nations Development Programme (UNDP). This indicator intends to evaluate the combined social and economic growth in a system (McGillivray, 1991). Moreover, the Physical Quality of Life Index (PQLI) is the other SLCA indicator which is composed of life expectancy at age one, infant mortality and literacy rate developed by David Morris in the mid-1970's at the Overseas Development Council (ODC) (Ferrans \& Powers, 1985).

\section{Integrated Mathematical and Computational Methodologies}

Mathematical and computational methodologies used for evaluating the integrated sustainability assessment (ISA) can fall into two main categories: (i) Computing and Information Science (CIS) and (ii) Integrated systems modelling. CIS focuses on both computing and informatics aspects facilitating ISA by analytical systems modelling such as data mining $\&$ analysis, artificial intelligence and dynamical simulation. However, the integrated systems modelling develops computational and quantitative sustainability assessment. Meanwhile, the computational aspect focuses on web-based databases, cloud computing cyberinfrastructure, advanced data acquisition, and artificial intelligence. Though, the quantitative aspect has also imple- 
mented sustainability assessment within operations research and management science (Videira, Antunes, Santos, \& Lopes, 2010).

The main component of integrated sustainability assessment is the lifecycle techniques themselves (Finkbeiner et al. 2010). Application of lifecycle principles is essential to achieve reliable sustainability assessment results. The lifecycle principles consider all types of lifecycles such as environmental, economy and social for all categories of sub-systems in a global system. As mentioned earlier, these sub-systems can be products and materials, organisations and stakeholders, supply chains, manufacturing processes, and etc. There are several mathematical and computational techniques to estimate the integrated sustainability assessments composed of environmental, economic and social impacts. Hitherto, different terms and indicators of the three pillars in sustainability assessment have been explained and discussed. The initial stage of Integrated Sustainability Assessment (ISA) is to identify and evaluate the critical corresponding sustainability criteria, indicators and metrics. This can be estimated by using Pareto principle based on 80-20 rule. The $80-20$ rule is also known as the law of the vital few states in which $80 \%$ of the effects arise from 20\% of the causes approximately (Azapagic, 1999). Further to this estimation, different mathematical and computational methodologies for ISA are introduced and explained briefly in the following sections. These integrated methodologies are: Klöffer technique, Multi-criteria decision analysis (MCDA) \& Multi-objective decision making (MODM), System Dynamics (SD), Agent-Based Modelling (ABM), Sustainability Network Analysis and Sustainability Optimization and Scenario Analysis.

\subsection{Klöepffer technique}

Klöepffer (2008) proposed that the integrated lifecycle in a sustainability assessment can be simply calculated by the summation of environmental, economic and social lifecycle assessment calculations, thus:

$$
L C S A=E L C A+L C C A+S L C A
$$

Although the Klöffer technique considers the triple pillars of sustainable development, it does not reflect on the complexity of interaction between these three dimensions. This is due to the linear equation with equal weighted components in the Klöffer method. To tackle this problem, different mathematical and computational methods have been developed which will be discussed in the following sections. Meanwhile, for instance, in a more recent computational method, the open source OpenLCA software offers an integrated and comprehensive method for analysing life-cycle impact assessment. This method considers different impact categories including normalisation and weighting factors (OpenLCA, 2016). The software includes features such as graphical modelling \& simulation and uncertainty approximation. 


\subsection{Multi-criteria decision analysis (MCDA)}

Achieving an integrated sustainability necessitate an integrated decision making. Decision problems consist of making choice(s), generating ranking(s), and sorting problem(s). These problems are often complex since they involve several criteria and aspects. Therefore, to create a sustainable decision, it is required to consider multiple criteria in the decision process so-called Multi-criteria decision analysis (MCDA) or Multi-objective decision making (MODM) analysis (Ishizaka \& Nemery, 2013). There are numerous methods to perform MCDA or MODA in a decision problem. Some of these methods include: Analytic Hierarchy Process (AHP), Analytical Network Process (ANP), Multi-Attribute Utility Theory (MAUT/UTA), and etc. In general, all MCDA methods are based on the following structure in order to develop an integrated and sustainable decision making. This structure involves as thus: (i) Criteria selection; to select $n$ sustainability criteria including technical, environmental, economic, and social criterion. (ii) Alternative selection; to select $m$ local (with respect to one specific criterion) and global (with respect to all criteria) alternatives. (iii) Grouped decision matrix development; where element $x_{i j}$ is the performance of $j$-th criteria $C$ of $i$-th alternative $A$. Besides, each criterion $c_{j}$ is weighted by a positive weight $w_{j}$ calculated as thus:

$$
\begin{aligned}
C & =\left[\begin{array}{lllll}
c_{1} & c_{2} & c_{3} & \ldots & c_{n}
\end{array}\right], \\
W & =\left[\begin{array}{lllll}
w_{1} & w_{2} & w_{3} & \ldots & w_{n}
\end{array}\right], \\
A & =\left[\begin{array}{lllll}
a_{1} & a_{2} & a_{3} & \ldots & a_{m}
\end{array}\right] .
\end{aligned}
$$

Moreover, a positive weight is assigned to a criterion to specify its relative importance among all criteria. The attributed weight arises from the variance and the independency degree of criteria, and the subjective preference of the decision-maker(s) (Wang, Jing, Zhang, \& Zhao, 2009). There are two main methods to calculate the weighted criteria: equal weights method and rank order weights method. In equal weights method, $w_{j}$ is calculated as below:

$$
w_{j}=\frac{1}{n}, \quad j=1,2,, n .
$$

Since the equal weights method does not consider the interactions between criteria, rank-order weighting method is proposed with criteria weights distribution as:

$$
w_{1} \geq w_{2} \geq w_{3} \geq \geq w_{n} \geq 0 \quad \text { where }, \sum_{i=1}^{n} w_{i}=1 .
$$

Furthermore, the rank-order weighting method is categorised into three different methods: (1) subjective weighting method (e.g., pair-wise comparison, analytical hierarchy process (AHP), etc.), (2) objective weighting method (e.g. entropy method, technique for order preference by similarity to ideal solution (TOPSIS), etc.) and (3) combination weighting method (e.g. ANP, MAUT) (Kirkwood \& Sarin, 1985). The 
weight of a criteria ranked to be $j$ th is calculated as (ZOU, YUN, \& SUN, 2006, Wang et al. 2009):

$$
\begin{aligned}
& \text { (1) } w_{1 j}=\frac{1}{n} \sum_{k=i}^{n} \frac{1}{k} \\
& \text { (2) } w_{2 j}=\frac{1-H_{j}}{n-\sum_{j=1}^{n} H_{j}}, \quad \text { where : } H_{j}=-\frac{1}{\ln m} \sum_{i=1}^{m} \frac{f_{i j}}{\ln f_{i j}}, \\
& \text { (3) } w_{3 j}=\frac{w_{1 j} w_{2 j}}{\sum_{j=1}^{n} w_{1 j} w_{2 j}},
\end{aligned}
$$

where, $f_{i j}$ is the joint probability density function, $k$ is the linear combination coefficient and $k \geq 0$ and $w_{1 j}$ and $w_{2 j}$ are subjective and objective weights respectively.

MCDA methods can be applied to develop different analysis such as (i) Stakeholders Analysis, (ii) Sensitivity and Uncertainty and Variability Analyses (e.g., Perturbation Analysis), (iii) Geographic Information Systems (GIS) and (iv) Data Envelopment Analysis (DEA). However, as mentioned earlier, to make the results more expedient for decision and policy makers, it is required to consider the uncertainty and dynamic interrelationships and interactions between the variables over time. In this regard, a number of appropriate methods are: Dynamic Multiple Criteria Decision Analysis (DMCDA), Stochastic Multi-Criteria Decision Making (SMCDM) (Chen, Li, \& He, 2010, Hu \& Yang, 2011) and fuzzy-MCDA (Chiou, Tzeng, \& Cheng, 2005, Jovanovic, Afgan, \& Bakic 2010), System Dynamics (SD), AgentBased Modelling (ABM) and Network. In the following, some of these methods are explained briefly.

As an extension of static MCDA problem, Dynamic-MCDA (DMCDM) considers variables over time across several criteria (Chen et al. 2010). Therefore, a set of time periods as matrix $T=\left[t_{1}, t_{2}, \ldots t_{k} \ldots t_{\tau}\right]$ will be added to the Equations 4 -7) and therefore $x_{i j}\left(t_{\tau}\right)$ represents the performance of criterion $c_{j}$ for alternative $a_{i}$ at $t_{\tau}$ time period. Therefore, in DMCDM, it is also required to collect alternative data over different time periods and criteria. Subsequently, aggregate value data $R=\left[r_{1}, r_{2}, \ldots r_{k} \ldots r_{\tau}\right]$ from different time periods can be calculated. Finally Data Envelopment Analysis (DEA) based results can be obtained by maximizing the possibility of alternative $V\left(a_{i}\right)$ as (Chen et al. 2010):

$$
V\left(a_{i}\right)=\max _{\varepsilon \leq r_{k} \leq 1} V\left(a_{i}\right)=\sum_{j=1}^{n} w_{j} \cdot v_{j}^{i}
$$

where, $v_{j}^{i}$ is the overall value of alternative $a_{i}$ over criterion, $c_{j}$ over $\tau$ time periods and expressed as thus:

$$
v_{j}^{i}=\sum_{k=1}^{\tau} r_{k} \cdot v_{j}^{i}\left(t_{k}\right),
$$

where $v_{j}^{i}\left(t_{k}\right)$ is the value of alternative $a_{i}$ on criterion $c_{j}$ at $t_{k}$ time period. Furthermore, stochastic MCDA is the other extension for static MCDA which includes probabilistic distribution for the decision alternatives across the decision criteria 
(Sparrevik, Barton, Bates, \& Linkov, 2012). This distribution reflects possible uncertainties due to the incomplete data. Moreover, fuzzy-MCDA is the other mathematical tool in the decision-making process under uncertain conditions using fuzzy sets (Zadeh, 1965). Although, fuzzy-MCDA is based on stochastic models, in this technique, decision alternatives uncertainties can be associated with fuzziness concerning the criterion weight assessment (Malczewski \& Rinner. 2015).

\subsection{System Dynamics (SD)}

The world as a global and complex system is constantly changing. Despite all available powerful mathematical and analytical methods and tools concerning sustainability, the interrelationship between different aspects of such a complex system necessitates a number of decision-makings and policy analysis. System Dynamics (SD) as a method, provides a networking technique to fulfil this concern in complex systems. The networking feature in SD method reflects the complex interactive behaviour of all systems components considering consequences of each action and decisions through the whole system. This is the main and fundamental aspect of SD that makes this method very powerful to solve complex systems compared to other methods. Long-term effective policies and decisions for sustaining a complex system are vital. Therefore, considering the frequent feedback of all components, variables and indicators over time are s key to decision making. System Dynamics creates a feedback loop between the decision made and the state of the system after implementation of such decisions (Sterman \& Rahmandad, 2014). This assists the decision maker in optimising the decision with minimum negative consequences (or side effects) within the system. Although an SD network intends to expand boundaries of global systems to consider the impacts of sub-systems on each other, there might be limits in the decision maker's understanding.

The global network of a complex system in the system dynamics method composes of three main parts, "stock" are accumulations of sub-system (i.e. agents in ABM method), "flow" as the rate of change between stocks within the network and "delay", which is the time-delayed interrelationship between the system quantitative measurements (Forrester. 1997) as illustrated in Figure 3 Delays can be caused by a variety of reasons such as inertia, delays in communication or any barrier that might delay the message passing between the entities. Regarding integrated sustainability, the three pillars of sustainability: environmental, economic, and social can be modelled using the network configuration in SD. Moreover, this modelling technique is capable of performing multiple scenarios. This comparison capability would assist a decision maker or a policy developer to compare different scenarios with a view to selecting the favourable solution. Therefore, combination of system dynamics and scenario analysis (which will be discussed later in this chapter), is a dominant methodology for decision making and subsequently optimisation of complex systems. Mathematically, the quantitative approach to model a complex system's sustainment using SD can be defined by a nonlinear first-order differential 


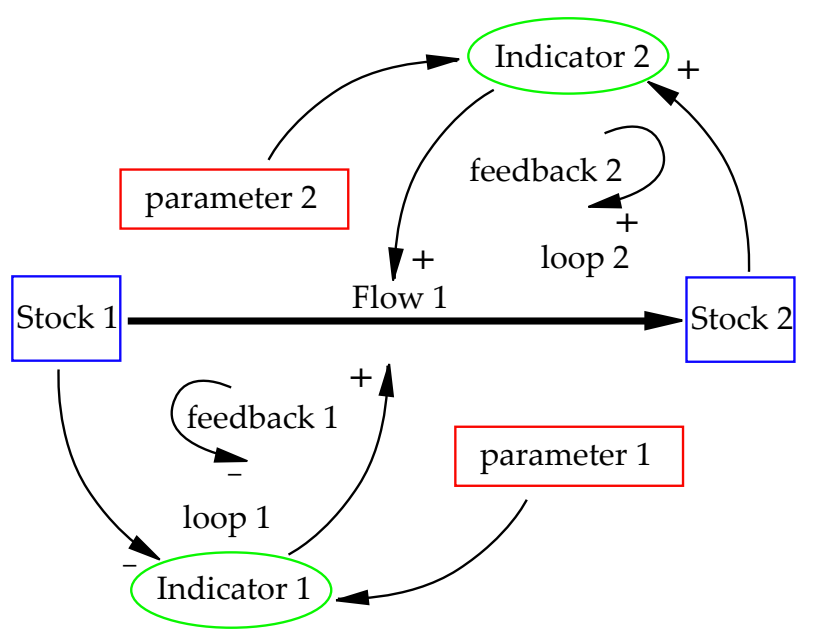

Fig. 3 System Dynamics (SD): Stock and Flow diagram; the sign of the links represents whether the variables at the two end move in the same $(+)$ or opposite $(-)$ directions; the sign for the loop represents whether it is a positive $(+)$ or negative $(-)$ feedback loop (Kirkwood 1998)

equation as:

$$
\frac{d}{d t} x(t)=A \cdot f\left(x, p_{i}\right)
$$

where $x$ is the state vector at time $t, d t$ is the discrete intervals of systems time length, $A$ is the constant matrix, $p_{i}$ is a set of parameters, $f$ is the nonlinear smooth evolution function affects the system's sustainability. Moreover, regarding the computational approach, there are a number of appropriate computer software packages to facilitate the development, modelling and simulation of SD models such as STELLA, iThink, Powersim and Vensim and AnyLogic (Halog \& Manik, 2011).

Ahmad and Simonovic, (2004) combined system dynamic approach and Geographic Information System (GIS) so-called Spatial System Dynamics (SSD) to study flood management in the Red River basin in Manitoba, Canada. The proposed approach considers the interaction between the components of the studied system using a feedback-based modelling through the dynamic behaviour of processes over time (Ahmad \& Simonovic, 2004). Moreover, Videira, et.al (2010) discussed the application of system dynamics approach on the integrated sustainability assessment framework to fulfil policy making in complex systems. The proposed framework intended to provide an improved insight into the dynamical behaviour of complex systems regarding long-term sustainability impacts on decision-making (Videira et al. 2010). Furthermore, $\mathrm{Xu}$, (2011) studied an integrated sustainability assessment of urban residential development using System Dynamics (SD) methodology. To explain the interaction between local and global aspects of the urban residential development system, SD has been combined with GIS approach. Consequently, the proposed method provide a better and comprehensive insight for decision maker 
(Xu, 2011). This can also be referred to as Urban Dynamic in some textbooks. Similarly, the dynamic behaviour of Triple Bottom Line (TBL) of sustainability in interaction with each other has been studied by Lee, et al. (2012) using the system dynamic method. The proposed approach studied the dynamical and multidimensional characteristics of a product service system with a view to assessing the integrated sustainability of the system through a comprehensive approach (Lee et al. 2012). In a more recent study, Abadi, et al. (2015) investigated the sustainability of a water resources management systems using system dynamics approach developed in Vensim software package. The study focuses on scenario analysis based on Analytical Hierarchy Process (AHP) for prioritising the sustainability indicators within the simulated scenarios. The results proposed an extensive insight for policy and decision makers in the management system of water resources (Abadi et al., 2015).

\subsection{Agent-Based Modelling (ABM)}

Agent-Based Modelling (ABM) is a computational method for simulating complex systems considering dynamic behaviour and non-linear interactions between multiple components so called agents. Although even today, the significance and decency in the majority of science is still based on mathematics, formulas, symbols and Greek letters, formulating most of the real and complex problems is extremely challenging. Therefore, computational methods offer this opportunity to study many of these complex phenomena in a system. In this regards, ABS is relatively a new approach to developing an integrated sustainability assessment in a complex system. Agents and sub-systems are introduced to the computational program with their corresponding metrics, properties and indicators. The overall aim of the simulation is to obtain the global consequences of the individual and interactive behaviour of all sub-systems in a given geographical area over a specific period. In contrast with the mathematical methods which represent components (the "agents") by variables, ABS introduces all agents into the modelling space based on their behaviours and characteristics. However, agent-based modelling use "what if" and "if-the" scenarios frequently to reflect the complex behaviour of a system which is clearly based on a mathematical formula. Therefore, agent-based models consist of agents (e.g. local or sub-systems), specific environment and domain (e.g. global system), and interaction rules between different agents (Barnes \& Chu, 2010).

Regarding lifecycle sustainability assessment, ABM technique is capable of combining the three pillars of sustainability in order to provide an integrated information for the decision maker as presented in Figure 4 ABM provides a nonlinear dynamic system to represent the behaviour of a complex global system with or without uncertainties within the sub-systems. Compared to the system dynamics method, ABM is more flexible for modelling a complex system with variable and multiple characteristics in sub-systems' behaviour and their interactions' structure (Davis, Nikolić, \& Dijkema, 2009). There is a wide range of ABM applications in integrated sustainability assessment concerning sustainable mobility (Whitmarsh \& Nykvist, 2008), 


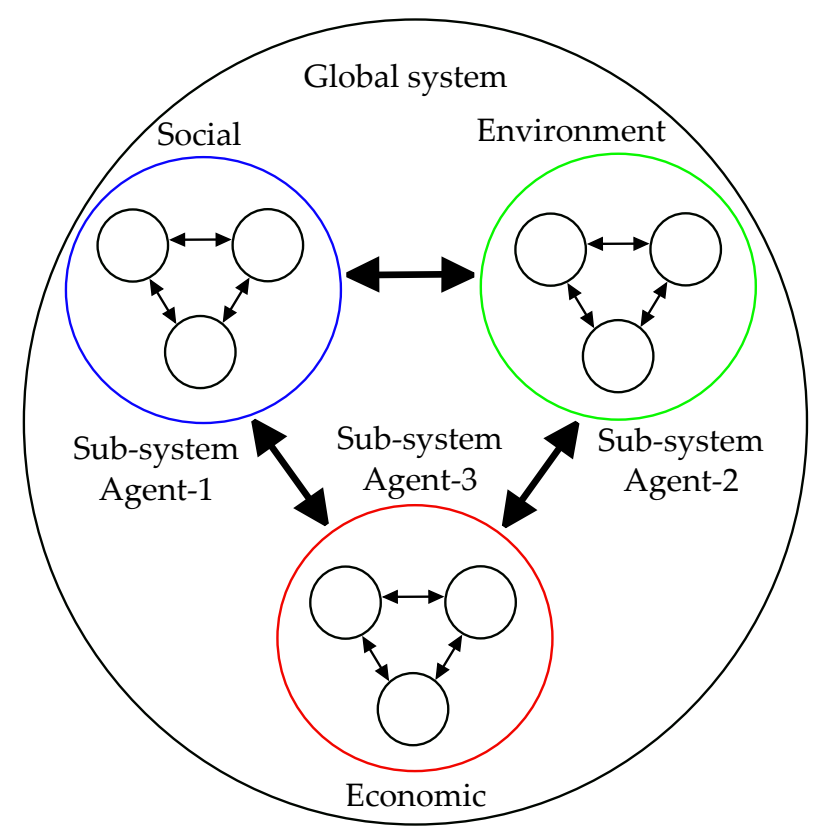

Fig. 4 Agent-Based modelling (ABM) presented the triple pillars of integrated sustainability assessment in a global system.

policy analysis in decision making (Tabara et al., 2008), integrated climate change modelling (Moss, Pahl-Wostl, \& Downing, 2001), integrated land system (Gaube et al. 2009) and etc. Agent-based modelling and simulation packages and software are based on Object-Oriented Programming (OOP) since each agent can be introduced as an object within the programming language. In OOP languages such as Simula, Java, Python, C++, NetLogo and etc. the focus is more on defining the logic when objects interact with each other in a complex system, than naming the entities and the programming itself. Some of the agent-based software packages are AnyLogic, MASON, MASS, and Swarm.

\subsection{Sustainability Network Analysis}

In a complex system, the interactive behaviour of sub-systems (i.e agents in ABM or stocks in SD methods) can be modelled as a graph comprising of discrete elements. In such a graph, the complex interactions between the elements can be represented as a network (Gonzales \& Parrott, 2012). This graph-based network can illustrate the complex behaviour of a system in a more straightforward manner, and can provide an appropriate tool to solve such problems using the network theory (Ahuja, Magnanti, \& Orlin, 1993). Sustainability Network Theory (SNT) aims to reflect the 
interaction between the three pillars of sustainability: environmental, economic and social. In this context, Network Analysis (NA) is introduced briefly as a powerful tool for assessing integrated sustainability within a complex system.

The initial step for using NA to assess sustainability in a global system is identifying and defining data on all elements, sub-systems and parameters (i.e agents in ABM or stocks in SD methods) using the simple input-output matrices. Subsequently, different corresponding indices are required to be calculated in order to measure the performance of the global system with regards to integrated sustainability assessment aspects. The method necessitates considering elements' constraints and boundaries individually and also when they are interacting with each other (Pizzol, Scotti, \& Thomsen, 2013). The output from network analysis provides information for decision makers. The applications for such a method includes assessment of energy consumption, environmental emissions, the total cost of the global system and etc. Performing integrated sustainability assessment as a network structure is key to studying the complex behaviour and consequently the welfare of for instance a society as a global system. This complex behaviour arises from mechanical and strategic interplays and flows. Concerning mechanical aspect, network structure mainly represents the system's behaviour as a linkage and/or a transmission path between different elements and agents. This connection can be modelled probabilistically within network. Whereas, the complexity of network is to be modelled through its structure and interactive outcomes, a more complicated techniques such as dynamic and/or equilibrium analysis are required (Jackson, 2010).

Prell, et al. have studied the sustainability of upland management in Peak District National Park in the UK using combine social network analysis and stakeholder analysis. They argued that the combined method would improve stakeholders' representation in the participating processes. Moreover, they concluded that the analysis provides more detailed information, despite the increase in time and costs (Prell, Hubacek, \& Reed 2009). In a similar study, Lim, et al. advanced the Prell's study by developing a software tool that identifies and prioritises stakeholders using social networks so-called StakeNet (Lim, Quercia, \& Finkelstein, 2010). The sustainability assessment of socio-ecological system has been discussed within Gonzaleś, et $a l$. research in which network analysis metrics are used. This study initially focused on the resilience of the system as one of the sustainability characteristics followed by the robustness feature using quantitative network analysis metrics (Gonzales $\&$ Parrott . 2012). In a more recent study, integrated network theory has been applied to generate an environmental lifecycle assessment in the Chilean electricity energy system (Kim \& Holme, 2015). Network theory as a framework for studying integrated sustainability assessment is still in its early stages of development. Since the network analysis is based on network configurations and complex dynamic analysis algorithms, an integrated methodology for network model development is still required. 


\subsection{Sustainability Optimization and Scenario Analysis}

Scenario analysis has been widely used in different applications for the past decades for optimisation studies, decision making, policy planning and risk and uncertainty assessment. Scenario analysis begins with identifying indicators and metrics which define the current and the future states of a system. The next step is to identify uncertainties and risks within the system. These factors are required to be prioritised and weighted and therfore different scenarios will be created. The three main sources of uncertainty in the integrated sustainability assessment are: (i) sustainable development and the corresponding physical, economic and social boundaries, (ii) the inherent subjectivity of assessment tools and (iii) the imperfection of the modelling tools and incomplete data to mimic the real situation (Ciuffo, Miola, Punzo, \& Sala, 2012). Since there is an inevitable connection between integrated sustainability assessment and risk (or uncertainty in this context), scenario analysis is an appropriate method for sustainability optimisation.

Optimisation and risk (or uncertainty) analysis for less complex systems can be obtained by linear programming methods such as sensitivity analysis. Sensitivity analysis can be applied as an extension to the integrated sustainability assessment's methods as discussed in the previous sections. However, for complex systems, stochastic programming methods such as Markov Chains, Markov Decision Process and Bayesian Network are more sensible to be applied in order to obtain the optimum behaviour of such systems. The stochastic programming methodology allows one problem to consider several scenarios simultaneously while scenarios present different consequences of random variables (Yang, 2010). This can provide an appropriate and comprehensive policy information for the decision-maker.

Application of scenario analysis for studying integrated sustainability of an industrial sector has been studied by Allwood, et al. (2008). They considered a wide-scale change to the clothing sector in the UK in order to predict the behaviour of this manufacturing sector in the future. Their results have been validated through extensive stakeholder discussions(Allwood et al., 2008). Moreover, Cinar and Kayakutlu, (Cinar \& Kayakutlu, 2010) developed scenario analysis by using Bayesian Networks for decision making and policy planning in an energy sector (Cinar \& Kayakutlu, 2010). Their proposed method assisted the decision makers in the studied energy sector by providing new policies.

\section{Resilience}

Moreover, when a complex system is disrupted by an event, the system emerges a property called "resilience" (Varga et al., 2009). The disruptive event is exposed to all the boundaries of the system domain; therefore loss of resilience can be described as an unstable dynamic response. The definition of resilience delivers a comprehensive perspective on performance which is the capability of a system to maintain its sustainable (or stable) behaviour. Meanwhile, measuring the interac- 
tive resilience (arises from interactive disruption) of a complex system is becoming more challenging. The interactive resilience in an interrupted complex system can be modelled mathematically and computationally using Agent-Based Modelling (ABM) approach (Phillips, 2010). This can be possible by using the Hill function (Barnes \& Chu, 2010) which is a mathematically efficient method to find the stationary points of a system. However, due to the inherent complexity of input and output variables in complex systems, the ABM approach is becoming intractable, computationally time-consuming and complicated. Therefore, such a problem can be tackled by combining ABM with the Gaussian Process emulator. This combined methodology would create a computationally fast and efficient probabilistic approximation model (Zitrou, Bedford, \& Daneshkhah, 2013). Furthermore, the probabilistic prediction results can be used directly to generate risk analysis (Daneshkhah \& Bedford, 2013), model calibration (Kennedy \& O'Hagan 2001), optimisation, forecasting the future, and etc., without re-evaluating the $\mathrm{ABM}$ at any additional data points. Finally, the combined methodology is capable of explaining the behaviour of the complex system that experiences changes and interruptions.

\section{Conclusions, Discussions and Further work}

Optimisation of complex systems is still a challenging problem as it contains numerous parameters and variables that are interacting with each other in a nonlinear manner. Functionality and flexibility assessment of a complex system is a key element for anticipating the systems' responses to changes and interruptions. This study discussed mathematical, and computational approaches for integrated sustainability assessment focused on solving the nonlinear dynamical behaviour of complex systems. Moreover, in conclusion, having this knowledge will allow the optimisation of systems' efficiency and would ultimately reduce the system's total costs. As discussed earlier, a complex system can be considered as a System of Systems (Hosseinian-Far \& Chang, 2015a) and its behaviour can be derived using mathematical modelling by employing differential equations or difference equations (Todorov \& Marinova 2011). Understanding resilience and sustainability of a system would assist the scientists, engineers, managers and in general, all the stakeholders to consider the lifecycle, benefits and drawbacks and the future of the system under development. This is also not an exception in information systems development. Cloud services and big data analytics are the emerging technologies within the computing and informatics discipline. Developing such information systems therefore, would require a thorough assessment and strategic view on the information systems' sustainability. The resilience of such a systems can also be studied for systems' safety and security assessment. In this chapter, we intended to offer a generic view on systems' sustainability and resilience and different approaches for their modelling, which can also be applied by the computer scientists when developing emerging IT systems. 


\section{References}

Abadi, L., Shamsai, A., \& Goharnejad, H. (2015). An analysis of the sustainability of basin water resources using Vensim model. KSCE Journal of Civil Engineering, 19(6), 1941-1949.

Ahmad, S., \& Simonovic, S. (2004). Spatial system dynamics: new approach for simulation of water resources systems. Journal of Computing in Civil Engineering, 18(4), 331-340.

Ahuja, R., Magnanti, T., \& Orlin, J. (1993). Network flows: theory, algorithms, and applications. Prentice hall.

Allwood, J., Laursen, S., Russell, S., de Rodríguez, C., \& Bocken, N. (2008). An approach to scenario analysis of the sustainability of an industrial sector applied to clothing and textiles in the UK. Journal of Cleaner Production, 16(12), 1234-1246.

Altieri, M. A. (1992). Sustainable Agriculture Sustainable agricultural development in Latin America: exploring the possibilities. Agriculture, Ecosystems \& Environment, 39(1), 1-21.

Azapagic, A. (1999). Life cycle assessment and its application to process selection, design and optimisation. Chemical engineering journal, 73(1), 1-21.

Barnes, D., \& Chu, D. (2010). Agent-based modeling. In Introduction to modeling for biosciences (pp. 15-77). Springer.

Benoît, C., Norris, G., Valdivia, S., Ciroth, A., Moberg, A., Bos, U., ... Beck, T. (2010a). The guidelines for social life cycle assessment of products: just in time! The international journal of life cycle assessment, 15(2), 156-163.

Benoît, C., Traverso, M., Valdivia, S., Vickery-Niederman, G., Franze, J., Azuero, L., ... Aulision, D. (2013). The methodological sheets for sub-categories in social life cycle assessment (S-LCA). United Nations Environment Programme (UNEP) and Society for Environmental Toxicology and Chemistry (SETAC).

Benoît, C., \& Vickery-Niederman, G. (2010). Social sustainability assessment literature review. The Sustainability Consortium.

Bertrand, N., Jones, L., Hasler, B., Omodei-Zorini, L., Petit, S., \& Contini, C. (2008). Limits and targets for a regional sustainability assessment: an interdisciplinary exploration of the threshold concept. In Sustainability Impact Assessment of Land Use Changes (pp. 405-424). Springer.

Brinsmead, T. S. (2005). Integrated Sustainability Assessment: Identifying Methodological Options (Tech. Rep.). Australia: Joint Academies Committee on Sustainability of the National Academies Forum.

Brundtland, G. (1987). Our common future: Report of the 1987 World Commission on Environment and Development. United Nations, Oslo, 1-59.

Chen, Y., Li, K., \& He, S. (2010). Dynamic multiple criteria decision analysis with application in emergency management assessment. In Systems Man and Cybernetics (SMC), 2010 IEEE International Conference (pp. 3513-3517).

Chiou, H., Tzeng, G., \& Cheng, D. (2005). Evaluating sustainable fishing development strategies using fuzzy MCDM approach. Omega, 33(3), 223-234. 
Cinar, D., \& Kayakutlu, G. (2010). Scenario analysis using Bayesian networks: A case study in energy sector. Knowledge-Based Systems, 23(3), 267-276.

Ciuffo, B., Miola, A., Punzo, V., \& Sala, S. (2012). Dealing with uncertainty in sustainability assessment. Report on the application of different sensitivity analysis techniques to field specific simulation models. EUR, 25166.

Daneshkhah, A., \& Bedford, T. (2013). Probabilistic sensitivity analysis of system availability using Gaussian processes. Reliability Engineering \& System Safety, 112, 82-93.

Davis, C., Nikolić, I., \& Dijkema, G. P. (2009). Integration of life cycle assessment into agent-based modeling. Journal of Industrial Ecology, 13(2), 306-325.

Elkington, J. (1994). Towards the sustainable corporation: Win-win-win business strategies for sustainable development. California management review, 36(2), 90-100.

Elkington, J. (2004). Enter the triple bottom line. The triple bottom line: Does it all add up, 11(12), 1-16.

European Union. (2014, 26 March). Environmental statistics and accounts [Computer software manual].

Ferrans, C., \& Powers, M. (1985). Quality of life index: development and psychometric properties. Advances in nursing science, 8(1), 15-24.

Fiksel, J. (2003). Designing resilient, sustainable systems. Environmental science \& technology, 37(23), 5330-5339.

Finkbeiner, ., Schau, E., Lehmann, A., \& Traverso, M. (2010). Towards life cycle sustainability assessment. Sustainability, 2(10), 3309-3322.

Forrester, J. W. (1997). Industrial dynamics. Journal of the Operational Research Society, 48(10), 1037-1041.

Gaube, V., Kaiser, C., Wildenberg, M., Adensam, H., Fleissner, P., Kobler, J., ... Smetschka, B. (2009). Combining agent-based and stock-flow modelling approaches in a participative analysis of the integrated land system in Reichraming, Austria. Landscape Ecology, 24(9), 1149-1165.

Gonzales, R., \& Parrott, L. (2012). Network theory in the assessment of the sustainability of social-ecological systems. Geography Compass, 6(2), 76-88.

Hacking, T., \& Guthrie, P. (2008). A framework for clarifying the meaning of Triple Bottom-Line, Integrated, and Sustainability Assessment. Environmental Impact Assessment Review, 28(2), 73-89.

Halog, A., \& Manik, Y. (2011). Advancing integrated systems modelling framework for life cycle sustainability assessment. Sustainability, 3(2), 469-499.

Hawkins, T., Hendrickson, C., Higgins, C., Matthews, H., \& Suh, S. (2007). A mixed-unit input-output model for environmental life-cycle assessment and material flow analysis. Environmental Science \& Technology, 41(3), 10241031.

Heijungs, R., Huppes, G., \& Guinée, J. (2010). Life cycle assessment and sustainability analysis of products, materials and technologies. toward a scientific framework for sustainability life cycle analysis. Polymer degradation and stability, 95(3), 422-428.

Hosseinian-Far, A., \& Chang, V. (2015a). Sustainability of Strategic Information 
Systems in Emergent vs. Prescriptive Strategic Management. International Journal of Organizational and Collective Intelligence, 5(4).

Hosseinian-Far, A., \& Jahankhani, H. (2015b). Quantitative and Systemic Methods for Modeling Sustainability. In M. Dastbaz, C. Pattinson, \& B. Akhgar (Eds.), Green information technoloy: A sustainable approach (chap. 5). UK: Elsevier Science.

Hosseinian-Far, A., Pimenidis, E., Jahankhani, H., \& Wijeyesekera, D. (2010). A review on sustainability models. In International conference on global security, safety, and sustainability (pp. 216-222).

Hosseinian-Far, A., Pimenidis, E., Jahankhani, H., \& Wijeyesekera, D. (2011). Financial Assessment of London Plan Policy 4A. 2 by Probabilistic Inference and Influence Diagrams. In Artificial intelligence applications and innovations (pp. 51-60). Springer.

Hu, J., \& Yang, L. (2011). Dynamic stochastic multi-criteria decision making method based on cumulative prospect theory and set pair analysis. Systems Engineering Procedia, 1, 432-439.

Ishizaka, A., \& Nemery, P. (2013). Multi-criteria Decision Analysis: Methods and Software. Wiley.

ISO 14004:2016. (2016, March). Environmental management systems - General guidelines on implementation (Standard). 1214 Vernier, Geneva, Switzerland: International Organization for Standardization.

ISO 14040:2006. (2006, July). Environmental management - Life cycle assessment - Principles and framework (Vol. 2006; Standard). 1214 Vernier, Geneva, Switzerland: International Organization for Standardization.

ISO 14044:2006. (2006, July). Environmental management - Life cycle assessment - Requirements and guidelines (Standard). 1214 Vernier, Geneva, Switzerland: International Organization for Standardization.

Jackson, M. (2010). An overview of social networks and economic applications. The handbook of social economics, 1, 511-85.

Jolliet, O., Margni, M., Charles, R., Humbert, S., Payet, J., Rebitzer, G., \& Rosenbaum, R. (2003). IMPACT 2002+: a new life cycle impact assessment methodology. The International Journal of Life Cycle Assessment, 8(6), 324330.

Jovanovic, M., Afgan, N., \& Bakic, V. (2010). An analytical method for the measurement of energy system sustainability in urban areas. Energy, 35(9), 39093920.

Kennedy, M., \& O'Hagan, A. (2001). Bayesian calibration of computer models. Journal of the Royal Statistical Society: Series B (Statistical Methodology), 63(3), 425-464.

Kim, H., \& Holme, P. (2015). Network theory integrated life cycle assessment for an electric power system. Sustainability, 7(8), 10961-10975.

Kirkwood, C. (1998). System Dynamics Methods. College of Business Arizona State University USA.

Kirkwood, C., \& Sarin, R. (1985). Ranking with partial information: A method and an application. Operations Research, 33(1), 38-48. 
Klöepffer, W. (2008). Life cycle sustainability assessment of products. The International Journal of Life Cycle Assessment, 13(2), 89-95.

Ladyman, J., Lambert, J., \& Wiesner, K. (2013). What is a complex system? European Journal for Philosophy of Science, 3(1), 33-67.

Lal, R., Ghuman, B., \& Shearer, W. (1990). Sustainability of different agricultural production systems for a rainforest zone of southern Nigeria. In Transactions 14th international congress of soil science, kyoto, japan, august 1990, volume vi. (pp. 186-191).

Lee, S., Geum, Y., Lee, H., \& Park, Y. (2012). Dynamic and multidimensional measurement of Product-Service System (PSS) sustainability: a Triple Bottom Line (TBL)-based system dynamics approach. Journal of Cleaner Production, 32, 173-182.

Leontief, W. (1970). Environmental repercussions and the economic structure: an input-output approach. The review of economics and statistics, 262-271.

Lim, S., Quercia, D., \& Finkelstein, A. (2010). StakeNet: using social networks to analyse the stakeholders of large-scale software projects. In Proceedings of the 32nd ACM/IEEE International Conference on Software EngineeringVolume 1 (pp. 295-304).

Malczewski, J., \& Rinner, C. (2015). Multicriteria decision analysis in geographic information science. Springer.

McGillivray, M. (1991). The human development index: yet another redundant composite development indicator? World Development, 19(10), 1461-1468.

Moss, S., Pahl-Wostl, C., \& Downing, T. (2001). Agent-based integrated assessment modelling: the example of climate change. Integrated Assessment, 2(1), 1730.

Ness, B., Urbel-Piirsalu, E., Anderberg, S., \& Olsson, L. (2007). Categorising tools for sustainability assessment. Ecological economics, 60(3), 498-508.

Office for National Statistics. (2013, July). Sustainable Development Indicators [Computer software manual]. London, UK: Author.

OpenLCA. (2016). http://www.openlca.org/.

Pezzey, J. (1989). Definitions of sustainability. UK Centre for Economic and Environmental Development.

Pizzol, M., Scotti, M., \& Thomsen, M. (2013). Network analysis as a tool for assessing environmental sustainability: Applying the ecosystem perspective to a Danish Water Management System. Journal of Environmental Management, $118,21-31$.

Pope, J., Annandale, D., \& Morrison-Saunders, A. (2004). Conceptualising sustainability assessment. Environmental Impact Assessment Review, 24(6), 595616.

Prell, C., Hubacek, K., \& Reed, M. (2009). Stakeholder analysis and social network analysis in natural resource management. Society and Natural Resources, 22(6), 501-518.

Rotmans, J., \& Asselt, M. (1996). Integrated assessment: a growing child on its way to maturity. Climatic Change, 34(3-4), 327-336. 
Schaltegger, S., Bennett, M., \& Burritt, R. (2006). Sustainability accounting and reporting (Vol. 21). Springer Science \& Business Media.

SETAC. (2016). Society of Environmental Toxicology and Chemistry. http://www2.setac.org/.

Shannon, C. (2001). A mathematical theory of communication. ACM SIGMOBILE Mobile Computing and Communications Review, 5(1), 3-55.

Silalertruksa, T., \& Gheewala, S. H. (2009). Environmental sustainability assessment of bio-ethanol production in Thailand. Energy, 34(11), 1933-1946.

Simon, H. (1991). The architecture of complexity. In Facets of systems science (pp. 457-476). Springer.

Smith, C., \& McDonald, G. (1997). Assessing the sustainability of agriculture at the planning stage. Journal of Environmental Management, 52(1), 15-37.

Sparrevik, M., Barton, D., Bates, M., \& Linkov, I. (2012). Use of stochastic multicriteria decision analysis to support sustainable management of contaminated sediments. Environmental science \& technology, 46(3), 1326-1334.

Statistical Office of the European Communities. (1982). Eurostatistik, Daten zur Konjunkturanalyse / [Statistisches Amt der Europaischen Gemeinschaften] = Eurostatistics, data for short-term economic analysis / [Statistical Office of the European Communities] [Journal]. Office for Official Publications of the European Communities Luxembourg.

Sterman, J., \& Rahmandad, H. (2014). Introduction to System Dynamics. Massachusetts Institute of Technology: MIT OpenCourseWare, http://ocw.mit.edu (Accessed). (License: Creative Commons BY-NC-SA)

Tabara, J., Roca, E., Madrid, C., Valkering, P., Wallman, P., \& Weaver, P. (2008). Integrated sustainability assessment of water systems: lessons from the Ebro River Basin. International journal of innovation and sustainable development, 3(1-2), 48-69.

Tibor, T., \& Feldman, I. (1996). Iso 14000: a guide to the new environmental management standards. Chicago, IL (USA) Irwin.

Todorov, V., \& Marinova, D. (2011). Modelling sustainability. Mathematics and Computers in Simulation, 81(7), 1397-1408.

Varga, L., Allen, P., Strathern, M., Rose-Anderssen, C., Baldwin, J., \& Ridgway, K. (2009). Sustainable supply networks: a complex systems perspective. Emergence: Complexity and Organization, 11(3), 16.

Videira, N., Antunes, P., Santos, R., \& Lopes, R. (2010). A participatory modelling approach to support integrated sustainability assessment processes. Systems Research and Behavioral Science, 27(4), 446-460.

Wang, J., Jing, Y., Zhang, C., \& Zhao, J. (2009). Review on multi-criteria decision analysis aid in sustainable energy decision-making. Renewable and Sustainable Energy Reviews, 13(9), 2263-2278.

Weisz, H., \& Duchin, F. (2006). Physical and monetary input-output analysis: What makes the difference? Ecological Economics, 57(3), 534-541.

Whitmarsh, L., \& Nykvist, B. (2008). Integrated Sustainability Assessment of mobility transitions: simulating stakeholders' visions of and pathways to sustainable land-based mobility. International journal of innovation and sustainable 
development, 3(1-2), 115-127.

Xu, Z. (2011, July). Application of System Dynamics model and GIS in sustainability assessment of urban residential development. In Proceedings of the 29th international conference of the system dynamics society. Washington, DC.

Yang, X. (2010). Applying stochastic programming models in financial risk management. The University of Edinburgh.

Zadeh, L. (1965). Fuzzy sets. Information and control, 8(3), 338-353.

Zitrou, A., Bedford, T., \& Daneshkhah, A. (2013). Robustness of maintenance decisions: Uncertainty modelling and value of information. Reliability Engineering \& System Safety, 120, 60-71.

ZOU, Z., YUN, Y., \& SUN, J. (2006). Entropy method for determination of weight of evaluating indicators in fuzzy synthetic evaluation for water quality assessment. Journal of Environmental Sciences, 18(5), 1020-1023. 